\title{
Issues Related to Academic Support and Performance of Division I Student-Athletes: A Case Study at the University of Minnesota
}

\author{
Mary Jo Kane, Perry Leo, and Lynn K. Holleran \\ University of Minnesota
}

In 2005, President Robert Bruininks launched an historic initiative-Strategic Positioning - to make the University of Minnesota one of the top three public research universities in the world. A key element of Strategic Positioning is to strengthen the quality of students' educational experiences through major academic initiatives. Because the President made the academic success of all students one of his highest priorities, he proactively initiated a Task Force that would address the academic performance of one critical group of students - student-athletes. The primary charge of the Task Force was to examine key issues surrounding studentathlete academic outcomes ranging from strengthening undergraduate retention and graduation rates, to improving coordination and delivery of academic support services. This was accomplished by:

- Collecting and analyzing longitudinal data from 1999 to 2007 to establish admission profiles of student-athletes, and to use these data to establish benchmark measures of student-athletes' academic performance;

- Assessing current practices concerning academic support and performance internal to the University and identifying best practices at similar academic institutions; and

- Developing and highlighting specific performance strategies that will foster student-athlete academic success rates.

This article discusses significant findings that emerged from an innovative statistical regression model, as well as key recommendations such as creating comprehensive programs to help student-athletes - especially those who are academically fragilesuccessfully transition into their academic and social life on a college campus.

\footnotetext{
Mary Jo Kane is with the School of Kinesiology, University of Minnesota. Perry Leo is with the Department of Aerospace Engineering and Mechanics, University of Minnesota. Lynn K. Holleran is Associate to the Vice President and Chief of Staff, Office of the President, University of Minnesota, Minneapolis, MN.
} 


\section{Introduction and Purpose of Student-Athlete Academic Task Force}

In the Fall of 2005, President Robert Bruininks and Provost Tom Sullivan convened a Task Force to review and address issues related to student-athlete academic outcomes at the University of Minnesota. Under the President's leadership, the University had launched an historic initiative called Strategic Positioning whereby the University of Minnesota ( $\mathrm{U}$ of $\mathrm{M}$ ) would aspire to become one of the top three public research institutions in the world. At the heart of this groundbreaking initiative was the academic experience and performance of $\mathrm{U}$ of $\mathrm{M}$ students. This aspirational goal, along with recent changes in NCAA legislation that focus on student-athlete outcomes at all Division IA institutions (Academic Progress RateAPR), and a Graduation-Rate Task Force charged by the Department of Athletics, created a unique opportunity to examine academic support services, programs, and structures to insure greater success for all $\mathrm{U}$ of $\mathrm{M}$ student-athletes.

The Academic Support and Performance for Student-Athletes Task Force was charged with the following responsibilities:

- Collect and analyze longitudinal data on student-athletes' admission pathways, academic progress, and graduation rates from the University;

- Establish benchmark measures using student-athletes' academic performance data;

- Assess current practices, opportunities, and challenges which impact academic support and performance for student-athletes throughout the University;

- Consult with key internal and external constituencies with the goal of improving student-athlete academic and postgraduate success rates and levels of student satisfaction;

- Assess the insights of faculty, academic leaders and staff, student athletes, alumni, and members of intercollegiate athletics regarding strategies for improving student-athlete outcomes and success; and

- Develop specific recommendations regarding support models, programs, and admission pathways that will enable student-athletes to achieve academic success.

An important factor that allowed the Task Force to meet its responsibilitiesand produce a comprehensive final report-was the depth and the breadth of its membership. The Task Force was cochaired by two full professors with extensive experience on issues associated with Division I intercollegiate athletics (e.g., faculty oversight). In addition, committee members represented key $\mathrm{U}$ of $\mathrm{M}$ offices, programs, and constituencies related to the academic performance of student-athletes ranging from athletics compliance to student advising to the Office of Admissions. [A complete list of those offices and programs as represented by committee membership is presented in Appendix A.] It should be noted that the Task Force-as reflected in its membership-was given a high-priority status within the University: Committee members served at the level of Director, Associate, or Assistant Director of their respective program or office. 


\section{Transforming the University of Minnesota Through Strategic Positioning: The Role of Student-Athletes}

As mentioned, a key component of Strategic Positioning is to strengthen the quality of students' educational experiences through major academic initiatives such as the Four-Year Graduation Plan. As part of this plan, Provost Sullivan announced new aspirational targets with the goal of significantly improving undergraduate retention and graduation rates. Because the President and Provost have made the academic success of all students one of their highest priorities, they proactively initiated a Task Force that would directly address the academic performance of one critical group of students-student-athletes.

To fulfill our charge, we focused on four essential tasks:

- Establish profiles of student-athletes on their admission pathways to the $\mathrm{U}$ of $\mathrm{M}$ and throughout their stay, and use these data to establish benchmark measures of student-athletes' academic performance;

- Assess current practices concerning academic support (e.g., student advising) internal to the University and identify best practices at similar academic institutions;

- Consult broadly with internal and external constituencies to gain insight into factors that might enhance or impede academic performance of studentathletes; and

- Develop specific recommendations related to academic support programs and highlight specific performance strategies that foster student-athlete academic success rates.

\section{Goals of the Task Force}

We framed our work around the goals of Strategic Positioning as they pertain to all $\mathrm{U}$ of $\mathrm{M}$ students - recruit, educate, challenge, and graduate outstanding students who become highly motivated lifelong learners, leaders, and global citizens. Such an approach builds a foundation for success by fostering a culture of excellence and accountability for results.

Strategic Positioning has created significant opportunities for a wide array of stakeholders within the University community, including student-athletes. The Task Force-guided by the commitment to improve the academic performance of student-athletes - was part of this larger transformation of the University. In sum, the Task Force played a powerful role within the broader mission of Strategic Positioning by:

- Exploring solutions and best practices to review and address critical issues surrounding the academic performance of student-athletes;

- Supporting faculty and staff who are dedicated to helping student-athletes achieve academic success; and

- Creating a culture that provides "access to success" so that student-athletes become lifelong learners and leaders. 


\section{Literature Review}

Sociologist Robert Benford reminds us that when it comes to the sport-reform movement in intercollegiate athletics, "Despite the cycles of reform activity and a plethora of in-depth reports, the problems [with college sports] seem to have gotten worse over time" (2007, p. 6). Nowhere does this seem to be more apparent than with the academic scandals that plague "big-time" college sports. And even when cheating (e.g., plagiarism) is not in play, many consider the low graduation rates-especially in the high-profile sports of football and men's basketball-to be a "scandal" in and of itself. Though much has been written about the role of athletics within higher education, given the primary charge of the Task Force, we confined our literature review to the academic performance of student-athletes at the Division I level.

There is an abundance of commentary, not to mention statistical reports, regarding the academic success (or nonsuccess) of student-athletes. As Matheson (2007) points out, even though student-athletes get what many perceive to be preferential treatment - from the availability of special academic support services to taking less demanding classes and classes unrelated to one's major-they routinely perform as well as, and in many cases better than, their nonathletic counterparts (Rishe, 2003; Shulman \& Bowen, 2001). Nevertheless, the NCAA has invested enormous time and effort trying to improve the academic performance of student-athletes. For example, the NCAA evaluates academic success rates and performance trends through such initiatives as the Graduation Success Rate (GSR), the Academic Success Rate (ASR), and their most recent effort at academic reform-the Academic Progress Rate (APR). [How these various rates are defined can be found at the NCAA's "Defining Academic Success" Web page, http://www2.ncaa.org/portal/ academics_and_athletes/education_and_research/academic_reform/defining_academic_reform.html]

Overall performance trends. With respect to the gold standard of academic success - overall graduation rates - the NCAA has traditionally relied on the Federal Graduation Rate (FGR), a federally mandated graduation rate which calculates the percentage of students who graduate within 6 years of enrollment. Considered by many to be the most conservative indicator of academic performance and achievement, FGR data show that student-athletes graduate (within 6 years) at higher or similar rates than do their nonathletic counterparts. For example, with respect to the 2000-2001 freshman cohort at the Division I level, the FGR is similar for student-athletes $(63 \%)$ when compared with the general student body (62\%) (NCAA, 2007c).

Performance trends by sex of student-athlete. Whether using GSRs, APRs or FGRs, female student-athletes outperform male student-athletes, as well as undergraduate students in general (NCAA, 2007b, 2007d). For example, among Division I student-athletes, the GSR for females who entered college in 2000 is higher $(87.3 \%)$ than for male student-athletes $(71.5 \%)$. Two reports issued by the Institute of Diversity and Ethics in Sport (IDES) reveal that both the GSR and APR of the 2007 women's NCAA basketball tournament teams were higher than 
the men's 2007 NCAA basketball tournament teams (2007a, 2007b). Based on their GSR, 98.4\% of the women's teams graduated at least $50 \%$ of their athletes, compared with only $64.1 \%$ of the men's teams (IDES, 2007b). The fact that female student-athletes routinely outperform their male counterparts could be attributed to the fact that many males over-identify with and invest more time in their athletic role often at the expense of their student role (Melendez, 2007).

Performance trends by race of student-athlete. Differences in graduation rates between White and African American student-athletes, while diminishing in some areas, remain a formidable challenge. According to the IDES (2006), White studentathletes graduate at higher rates (66\%) than African American student-athletes (52\%), and African American males have the lowest graduation rates (48\%) of all student-athletes. And though it is the case that overall, male student-athletes graduate at a higher rate than male non student-athletes, the graduation rates for men's basketball and football lag far behind those of male nonathletes at all Division I colleges and universities. Matheson (2007) has suggested that a contributing factor related to the low graduation rates in these two high-profile sports could be that scholarship athletes are much more likely to be drawn from the African American community, which historically has a much lower graduation rate when compared with other racial and ethnic groups. For example, in Division I basketball, $42 \%$ of the female players and $62.6 \%$ of the male players are African American. The African American males graduate at a rate of $51 \%$ compared with White males, who graduate at a rate of $76 \%$. Similar trends exist for female basketball players: White females graduate at a rate of $89 \%$ compared with African American females, who graduate at a rate of $72 \%$ (IDES, 2007a).

It should be noted that in spite of the patterns outlined above, more African American student-athletes (52\%) than ever before are graduating from college, and they are graduating at a higher rate than African American nonathletes (43\%) (IDES, 2006).

Performance trends by sport type. Academic performance as measured by graduation rates clearly varies across the sport with which the student-athlete is associated. With respect to men's sports, and relying on APR averages, the lowest performing sports are basketball (927.7), football (931.1), and baseball (935), while those sports with the highest APRs include ice hockey (969.6), swimming and diving (966.8), and lacrosse (967.3). In terms of the APR averages for women's sports, the three lowest performing sports are basketball (959.9), indoor track (964.2), and outdoor track (965.6), while the highest performing sports include rowing (984.3), lacrosse (983.3), and field hockey (983.1) (Hosick, 2007).

Summary of performance trends. Although challenges still persist, improvements in the graduation rates of student-athletes over the last few years appear to be the result of a variety of factors such as enhanced student-athlete academic support programs, strengthened NCAA academic criteria for entering high school students, stronger social support networks within the student-athlete community, and improved psychological support services. Recent trends surrounding the academic achievement and performance of student-athletes can be construed as quite positive. As mentioned, student-athletes are in most cases outperforming their nonathlete 
counterparts, and racial disparities are narrowing though they continue to represent one of the most significant challenges within all of higher education.

\section{Method}

\section{Data Collection Procedures: Establish and Analyze Longitudinal Baseline Data}

Individuals in the Office of Institutional Research and Reporting and the Office of the Registrar undertook data collection and analysis. In the final report submitted to the President and Provost in January, 2007, data were collected from 1999 (this was the first year comprehensive data from PeopleSoft-a computer-based data warehouse-were available) through Fall, 2006. For the 2008 NCAA presentation, we also included demographic and performance data for the 2006-2007 studentathlete cohort. Note that the results presented below include information from this additional cohort.

\section{Data Analysis}

There were two phases of data collection and analysis:

- Phase I: Establishing demographic and academic performance profiles of student-athletes through the use of Descriptive Data

- Phase II: Identifying key factors which contribute to the academic success rates of student-athletes employing an Innovative Statistical Model

In Phase II, we moved beyond descriptive profiles of student-athletes and examined key factors (as well as the relative weight of each of these factors), which may contribute to the academic performance of student-athletes. Toward that end, an innovative regression/predictor model that isolated variables significantly correlated with academic success was developed by John Kellogg and Ron Huesman (Office of Institutional Relations) specifically for our Task Force. Their approach employed "survival analysis" as a way to identify factors that could impact a studentathlete's ability to persist and graduate over time (a more detailed description of this particular technique is provided on pages 109-110).

In addition to Phases I and II, we collected information from NCAA databases and recent analyses of academic performance trends of General College (GC) student-athletes. General College had a particular relevance for the issues under consideration because its mission was to serve as an access point to the University for high-potential students who may not meet the competitive admission standards present in other U of M Colleges. Because General College offered support services for all its students similar to those offered by the academic counseling center for student-athletes, studies of the performance of GC students served as a useful parallel to the overall work of the Task Force. In 2006, General College was merged with other units in the University to form the current College of Education and Human Development (CEHD). 


\section{Variables Related to Demographic and Academic Performance Profiles of Student-Athletes}

A significant part of our charge was to establish baseline information. Therefore, a primary goal of Phase I was to gather and analyze longitudinal data. By doing so, we were able to give the University a compelling set of data that can be used to develop critical models, strategies, and benchmarks for future success. In addition, gathering baseline data on longitudinal trends allows the University to comprehensively examine student-athletes' admissions pathways, academic progress, and graduation rates.

Phase I encompassed two key areas or categories of data collection and analysis:

- Variables related to the demographic profile of student-athletes admitted to the University, including:

High school class rank

Standardized test scores

Special admit status

State/country of origin

Admitting college

Eligibility for Pell grants

First generation college student

- Variables related to student-athletes' academic performance once enrolled at the University, including:

$\mathrm{U}$ of $\mathrm{M}$ cumulative GPA (each term)

$\mathrm{U}$ of $\mathrm{M}$ term GPA

College and department affiliation (each term)

Academic major (each term)

Whether student-athlete satisfied academic eligibility requirements (each term)

Number of overall credits (each term)

Number of degree credits toward major (each term)

Number of credits short of graduating

Number of Ws, Fs, and Ds

Remaining eligibility (each term)

Student-athlete graduated or did not graduate (4-, 5-, 6-year periods)

All data were analyzed through a two-tier process. First, we examined overall trends for each of the two categories cited above, and second, we separated the data by:

- Year in school

- Sport

- Gender 
- Ethnicity

- Graduation status (graduated or not) after 4, 5, and 6 years

- At-risk status: Defined as an entering high school student either below the 50th percentile in his/her class or with an ACT score of less than 20 or an SAT score of less than 940. This definition of "at-risk" is used by the Office of Admissions for all $\mathrm{U}$ of $\mathrm{M}$ students.

\section{Glossary of Terms}

Students at the University of Minnesota are admitted into specific colleges. The primary freshman admitting colleges are presented below. The other College mentioned in this report is the College of Continuing Education (CCE). While this particular College does not admit freshman, CCE does offer degree programs primarily through its Inter-College Program (ICP) where students design their own academic major.

CALA: College of Architecture and Landscape Architecture

CCE: College of Continuing Education

CEHD: College of Education and Human Development

CHE: College of Human Ecology

CLA: College of Liberal Arts

CFANS: College of Food, Agricultural and Natural Resource Sciences

CSOM: Carlson School of Management

GC: General College

ICP: Inter-College Program

IT: Institute of Technology

Student-athletes receive academic student advising at the McNamara Student Advising Center (MAC).

\section{Results}

All findings that follow refer to graduation rates/trends based on a subgroup of student-athletes and non student-athletes who entered the $\mathrm{U}$ of $\mathrm{M}$ between Fall, 1999, and Spring, 2003, and thus had at least four years to graduate. For a more detailed breakdown of all Task Force results related to the demographic profiles and academic performance profiles of student-athletes, see http://www.academic. umn.edu/provost/reports/athletics.html.

\section{Phase I Results: Key Findings}

Demographic profile of incoming student-athletes. From 1999 to 2007, approximately 1,750 student-athletes and 63,050 non student-athletes were enrolled at the University of Minnesota. The gender and racial profiles of this group are provided in Figure 1. 


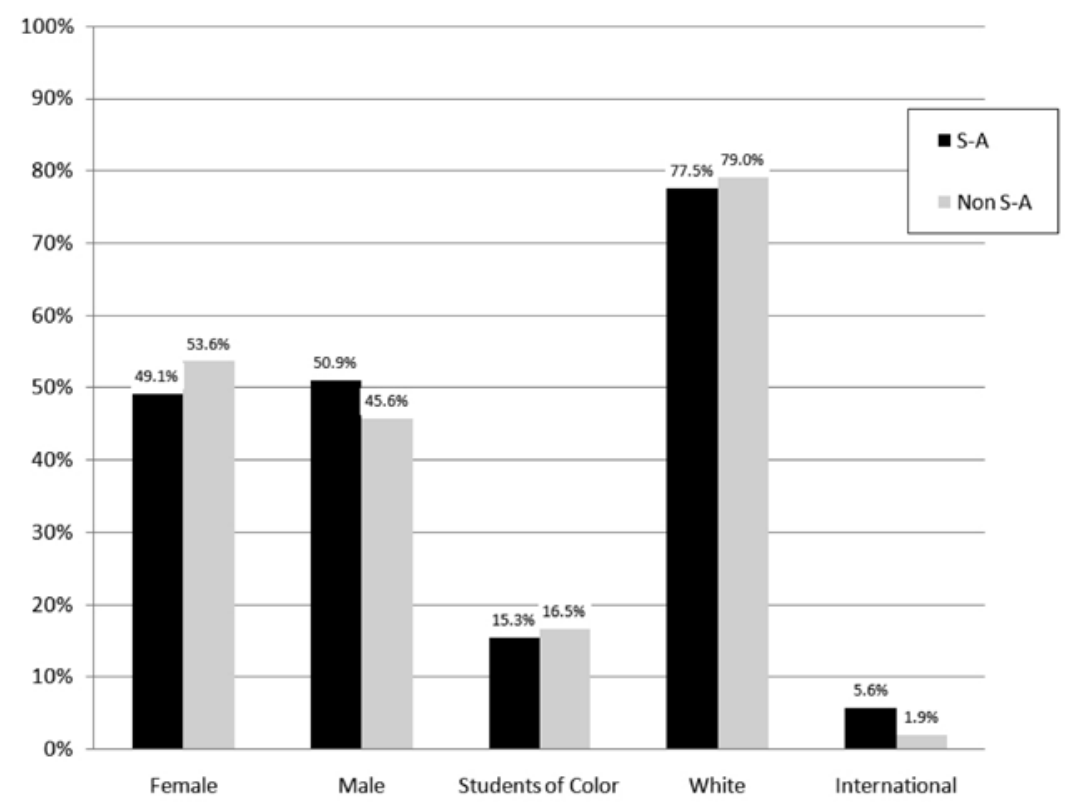

Figure 1 - Comparative data for student-athletes vs. non student-athletes: demographic profile.

- The percentage of students of color was higher among male student-athletes $(21.3 \%)$ than among female student-athletes $(9.1 \%)$

- Approximately $55 \%$ of female student-athletes were tendered, while approximately $70 \%$ of male student-athletes were tendered

- Just over $50 \%$ of student-athletes came from Minnesota, about $20 \%$ came from states with some form of reciprocity (primarily Wisconsin), while the remaining $30 \%$ came from other states or countries

- $91.4 \%$ of student-athletes enrolled directly from high school, while $8.6 \%$ transferred from other institutions (2- and 4-year colleges and universities)

- Approximately $46 \%$ of all student-athletes enrolled in CLA, 31\% in GC, and $22 \%$ in other colleges (IT, CSOM and CFANS)

Among female student-athletes, 57\% enrolled in CLA and $18 \%$ in GC

Among male student-athletes, $36 \%$ enrolled in CLA and $44 \%$ in GC

$62 \%$ of student-athletes of color enrolled in GC

Academic performance profile of student-athletes. One predictor of future academic success is high school class rank. With respect to the 1,750 studentathletes and the 62,050 non student-athletes enrolled at the U of M from 1999 to 2007, their class ranks are provided in Figure 2.

- Female student-athletes were more likely to come from the top $25 \%$ of their class $(71 \%)$; this trend did not occur for male student-athletes (only $40 \%$ ) 


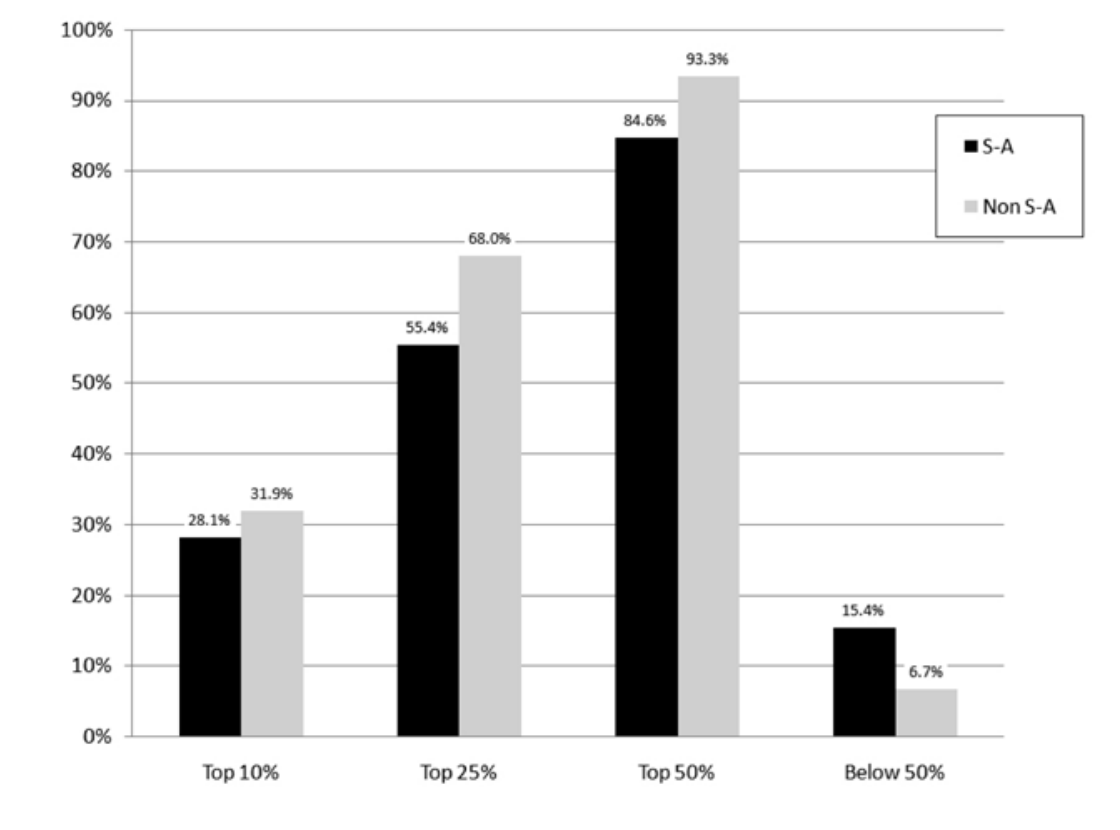

Figure 2 - Comparative data for student-athletes vs. non student-athletes: entering highschool class rank.

- Among student-athletes of color, approximately $30 \%$ were in the top $25 \%$ of their high school class while $32.4 \%$ were in the bottom $50 \%$

- On the ACT exam, $4.5 \%$ of student-athletes scored between 31 and 36; 34.2\% scored between 25 and 30; 49.3\% scored between 19 and 24; and 12.0\% scored below 19

- Female student-athletes performed better than males on the ACT, particularly between scores of $25-30$ (40\% vs. $28.4 \%$ ) and $31-36$ (7.2\% vs. $1.9 \%$ )

- Approximately $45 \%$ of all student-athletes of color scored below 19

Demographic profile of at-risk student-athletes. Recall that for the purposes of this study, "at-risk" status is defined as a student entering high school either below the 50th percentile in his/her class or with an ACT score of less than 20 or an SAT score of less than 940 . Figure 3 provides the percentages of at-risk studentathletes vs. at-risk non student-athletes overall, as well as their gender and racial background, respectively.

- Of those female student-athletes classified as at risk, basketball had the largest percentage of at-risk student-athletes (53\%) and rowing the smallest (8\%)

- Of those male student-athletes classified as at risk, football had the largest percentage of at-risk student-athletes (48\%) and swimming the smallest (20\%)

- $81.7 \%$ of all at-risk student-athletes were enrolled in GC; $14.3 \%$ in CLA; and $4 \%$ in all other Colleges 


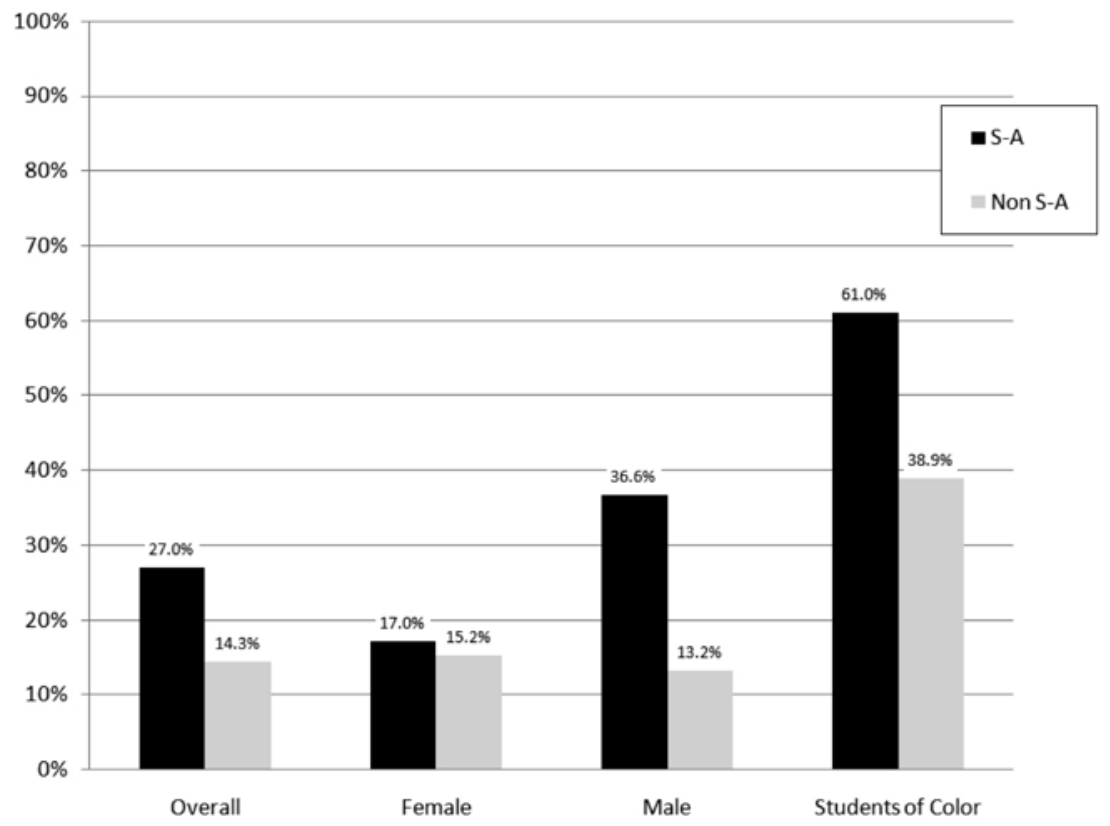

Figure 3 - Comparative data for at-risk student-athletes vs. at-risk non student-athletes: overall, gender, and racial breakdown.

Academic performance profile of at-risk student-athletes. The benchmark measure of academic success is graduation rate. Figure 4 highlights the graduation rates for at-risk student-athletes vs. at-risk non student-athletes overall, as well as for 6-, 5- and 4-year rates, respectively. [Note that the findings described below are from the original Task Force report and do not include additional data from the 2006-2007 cohort because of time constraints in the Office of Institutional Reporting.]

- Approximately $53.3 \%$ of at-risk student-athletes in the 1999-2003 cohorts had not graduated

- The average GPA for student-athletes classified as at risk was 2.48 and 3.09 for those not classified as at risk

- The average GPA was 2.8 for at-risk students who graduated and 2.25 for those who didn't graduate

- The overall number of Ws, Fs, and Ds was significantly higher for at-risk student-athletes compared with not-at-risk student-athletes

- The average number of Fs was 2.80 for at-risk student-athletes who didn't graduate versus 1.08 for those who did graduate 


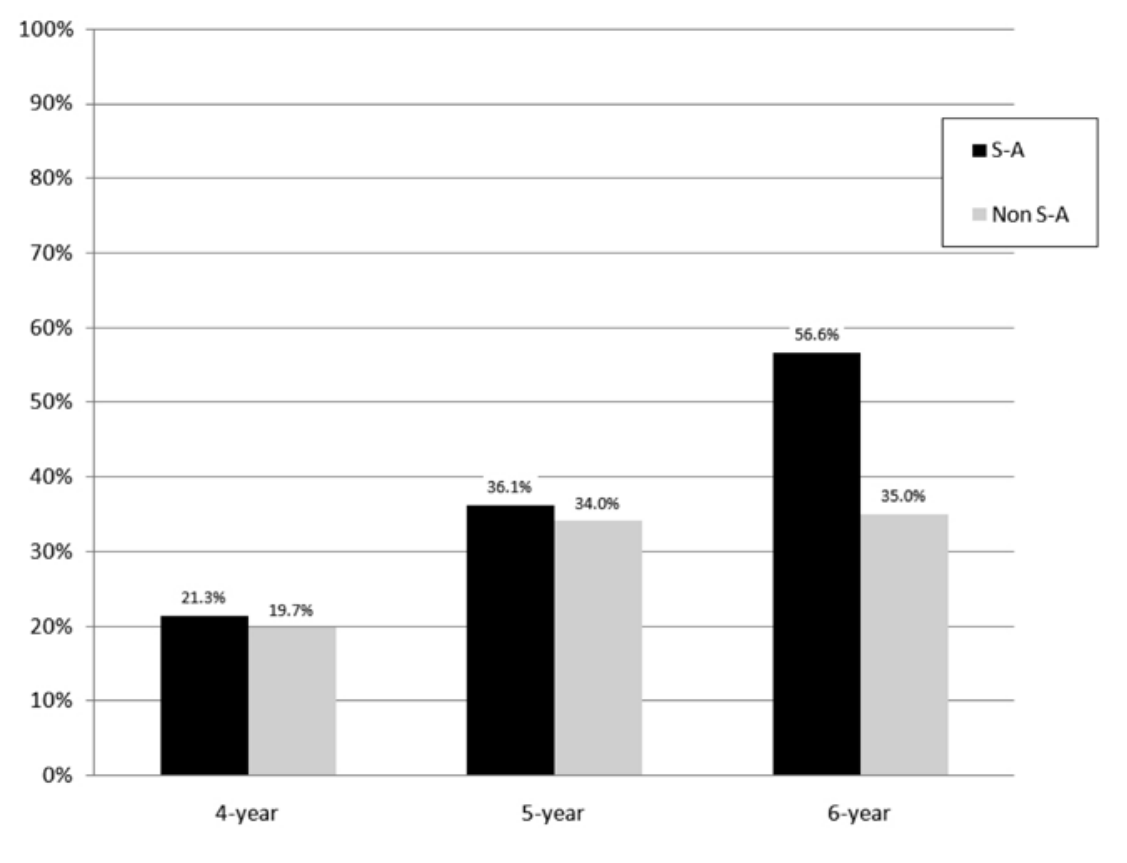

Figure 4 - Comparative data for at-risk student-athletes vs. at-risk non student-athletes: graduation rates.

\section{Phase I Summary}

Based on these findings, it seems safe to assume that those student-athletes who will most likely not graduate can be identified long before they leave the University. A critical question therefore becomes: When, where, and how do we intervene with at-risk student-athletes? This question in particular guided much of our work as we formalized our conclusions and made specific recommendations to enhance the overall academic success of student-athletes.

\section{Regression Analysis: Identifying Key Factors That Contribute to Academic Success Through an Innovative Statistical Model}

As mentioned, in the second phase of our analysis we moved beyond descriptive profiles and examined factors that may contribute to academic performance trends of student-athletes. More specifically, we employed "survival analysis" as a way to identify what scholars call "dynamic factors" that influence a student-athlete's ability to persist and graduate (for our purposes here, graduation or retention) as 
a function of time (student credit hours). As a statistical and methodological technique, survival analysis has been used in the fields of biology, economics, and the social sciences (Box-Steffensmeier \& Jones, 1994; Schmidt \& Witte, 1988).

The ability to explicitly model the dynamic nature of events-not only if a student drops out of school but when and under what circumstances-is a powerful tool because it offers insight into global factors influencing a student's performance (e.g., their race or gender), as well as local, time-specific factors on the ground (e.g., family emergency, low GPA for one semester) that identify when a student is most vulnerable to not continuing. While survival analysis offers information related to both these levels of analysis, we choose to focus only on how global factors influence academic success because time-sensitive issues such as a death in the family are more easily addressed and monitored as an advising/counseling issue rather than as a broader institutional factor.

The goal of this model in particular, and Kellogg's and Huesman's research in general (see reference under Radcliffe, Huesman, \& Kellogg, 2007a, 2007b), was to develop a practical application to help the $\mathrm{U}$ of $\mathrm{M}$ enhance student-athlete success by identifying at-risk students. Their multivariate approach answered the key question: "What specific student characteristics help predict academic success vs. departure?" The dependent variable_-academic success_-was defined as graduation within 6 years from entry for new freshman.

The input or independent variables were:

- Ethnic origin (students of color vs. not students of color)

- Gender

- Sport type (revenue vs. nonrevenue)

- Tender status (tendered vs. not tendered)

- ACT/SAT score (SAT scores were converted to an equivalent ACT score)

- Entrance college (GC vs. not GC, and CLA vs. not CLA)

- Number of Fs first semester

- Number of Ds first semester

- Number of Ws first semester

- Number of Cs first semester

- Ratio of units attempted to units completed first semester

- At-risk status

These particular variables were selected as representative of a student-athlete's entering demographic profile (e.g., sport type, gender). First-semester performance measures were targeted because studies conducted by General College showed a strong and positive correlation between first-semester performance (with respect to overall GPA) and graduation rates.

\section{Phase II Results: Key Findings}

Results indicated that only five of the input variables correlated with academic success. In decreasing order of significance they were: 
- Ratio of units attempted to units completed, first semester

- Ethnic origin (students of color vs. not students of color)

- Number of Cs first semester

- Entrance college (GC vs. not GC)

- Number of Ws first semester

Although these specific variables did not reveal the entire story of critical factors related to academic success ( $28 \%$ of the variance was explained in the model, though this percentage is considered significant in relevant academic fields of study), the regression model we employed correctly predicted $70 \%$ of the unsuccessful student-athletes and $80 \%$ of the successful student-athletes from the full cohort. In addition, the data were reanalyzed using a discriminant function analysis (cluster analysis) rather than a logistic regression analysis; results from this follow-up analysis were essentially identical.

\section{Unanticipated Findings}

Results from the logistic regression model revealed an unanticipated - though highly significant - trend related to academic performance. When academic success was defined as either having already graduated or being currently enrolled at the $U$ of $M$ and on track to graduate, two important subgroups of student-athletes emerged:

- Underachievers: Student-athletes who were predicted to succeed but did not do so; and

- Overachievers: Student-athletes who were predicted not to succeed but did so.

Once these two groups were identified, we examined their individual transcripts in detail. We were particularly interested in understanding the profiles of those student-athletes who succeeded despite the odds (i.e., "overachievers"), as well as those student-athletes who appeared to have the tools to succeed academically but failed to do so (i.e., "underachievers"). Their demographic profiles are highlighted in Table 1.

With respect to overachievers, what immediately stands out is that $81 \%$ of them are male. In addition, $47 \%$ are White, $28 \%$ are Black, and $16 \%$ are international students. The sport with which overachievers are affiliated appears not to make a great deal of difference except for football (34\%). Underachievers are more evenly distributed by gender ( $44 \%$ female vs. $56 \%$ male). As was the case with overachievers, most of them are White $(72 \%)$, Black (12\%), or international students $(10 \%)$. In contrast to overachievers, underachievers were widely distributed across both women's and men's sports.

Though it is important to further investigate which factors may have contributed to overachieving student-athletes, it should be noted that they represented only $2.29 \%$ of student-athletes overall. Committee members expressed concern about underachievers (who represented $7.43 \%$ of student-athletes overall) because, based on the survival analysis model, they should have succeeded academically but failed to do so. Issues related to why this might be the case-and what steps 
Table 1 "Overachiever" and "Underachiever" Student-Athlete Demographic Profile

\begin{tabular}{|c|c|c|}
\hline & $\begin{array}{c}\text { Percentage } \\
\text { of overachievers } \\
(N=32)\end{array}$ & $\begin{array}{c}\text { Percentage } \\
\text { of underachievers } \\
(N=103)\end{array}$ \\
\hline \multicolumn{3}{|l|}{ Gender } \\
\hline female & 19 & 44 \\
\hline male & 81 & 56 \\
\hline \multicolumn{3}{|l|}{ Race } \\
\hline American Indian & 0 & 1 \\
\hline Asian & 0 & 2 \\
\hline African American & 28 & 12 \\
\hline Hispanic & 3 & 2 \\
\hline international & 16 & 10 \\
\hline unknown & 6 & 2 \\
\hline White & 47 & 72 \\
\hline \multicolumn{3}{|l|}{ Sport, men's } \\
\hline baseball & 3 & 5 \\
\hline basketball & 0 & 2 \\
\hline football & 34 & 15 \\
\hline golf & 6 & 3 \\
\hline gymnastics & 3 & 4 \\
\hline hockey & 0 & 9 \\
\hline swimming & 13 & 5 \\
\hline tennis & 3 & 2 \\
\hline track/cc & 13 & 7 \\
\hline wrestling & 6 & 5 \\
\hline \multicolumn{3}{|l|}{ Sport, women's } \\
\hline basketball & 3 & 3 \\
\hline golf & 0 & 3 \\
\hline hockey & 0 & 4 \\
\hline rowing & 6 & 5 \\
\hline soccer & 0 & 6 \\
\hline softball & 0 & 3 \\
\hline swimming & 0 & 5 \\
\hline tennis & 0 & 1 \\
\hline track/cc & 6 & 13 \\
\hline volleyball & 3 & 3 \\
\hline \multicolumn{3}{|l|}{ Entry college } \\
\hline CLA & 28 & 49 \\
\hline $\mathrm{GC}$ & 60 & 34 \\
\hline Exit college & (graduated) & (withdrew) \\
\hline $\mathrm{CCE}$ & 19 & 6 \\
\hline CLA & 34 & 50 \\
\hline CEHD & 28 & 9 \\
\hline $\mathrm{GC}$ & $\mathrm{n} / \mathrm{a}$ & 15 \\
\hline IT & 3 & 7 \\
\hline
\end{tabular}

Note . CLA $=$ College of Liberal Arts; $\mathrm{GC}=$ General College $; \mathrm{CCE}=$ College of Continuing Education; CEHD = College of Education and Human Development; IT = Institute of Technology. 
the $\mathrm{U}$ of $\mathrm{M}$ should take to address the problem — are highlighted in detail under Recommendation 4 toward the end of this report.

A second (and equally important) unanticipated finding involved the challenges we faced when trying to collect and analyze data. We refer to the present state of data warehousing at the U of $\mathrm{M}$ as "here, there, and everywhere." Though Task Force members had every confidence that the data (and findings) highlighted throughout this report are robust and reliable, we faced a number of significant hurdles when attempting to collect data related to the primary issues under consideration. For example, one of the first things we discovered was that critical data related to the academic performance of student-athletes were stored in disparate places across the University ranging from the Athletic Department, to the Compliance Office, to General College. In addition, different units often relied on completely different data sets.

Not surprisingly, this situation often resulted in missing data, duplication of effort, and data that were not always up to date. As a result, tracking and monitoring the progress of student-athletes became much more complicated, time-consuming, and cumbersome. This could be particularly problematic for those most in need of more intensive oversight-at-risk student-athletes.

It should be emphasized that those individuals responsible for collecting, analyzing, and tracking data related to the academic profiles and performance of student-athletes are keenly aware of these problems and support the recommendations made in the Task Force report. Please note that these recommendations were made at both an immediate tactical level and at a longer term research and development level.

\section{Recommendations for Achieving Academic Success for $U$ of M Student-Athletes}

Based upon the results outlined above, we made five specific recommendations to University administrators.

\section{Recommendation 1}

Formalize, standardize, and streamline data collection of student-athletes' academic performance by creating a centralized database that can be used by Athletics, Compliance, Admissions, the McNamara Academic Center, and other relevant units across the University.

As mentioned, we have a current system that is in need of significant overhaul. Critical data related to student-athletes are in disparate places across the University and need to be stored in one central location. For example, individual paper files are kept in the Compliance Office, whereas other information is housed in the McNamara Student Advising Center or the Athletic Department and filed electronically. The practical effect of this noncentralized, nonstandardized system is that a great deal of effort is required to accurately track the progress of student-athletes toward a degree, not to mention their eligibility and APR status. In addition, athletic advisers in the MAC and at the academic department level routinely report difficulty in communicating consistent information to student-athletes. A more streamlined, 
standardized, and centralized system for data collection and analysis will allow for ongoing and consistent tracking of student-athletes' academic progress. In sum, such a system will create more efficient and effective ways to update, monitor, and access both routine and important information.

As part of our research, we gathered information on current best practices at other peer institutions. We discovered that the University of California at Berkeley has one of the best database systems in the country for profiling, tracking, analyzing, and reporting information related to student-athletes. The "Berkeley Model" uses a program called FileMaker Pro that includes personal information, information relevant to particular sports, current academic status, travel schedule, eligibility information, transcripts, and class schedules, as well as athletic advisor comments and e-mails, and college advisor comments and e-mails. The database is also used to collect information on prospective student-athletes during the recruiting phase. Our Task Force recommended implementing this or a similar system.

Related to the creation of a centralized, standardized database, we recommend hiring a "data czar" to implement and oversee the system. Though we are reluctant to make recommendations related to personnel matters, it became clear in the course of our conversations that unless some individual is tasked with data collection procedures and oversight as their primary responsibility, the current system will continue to be done on a piecemeal basis and many profiling, tracking, and reporting needs will simply "fall through the cracks."

\section{Recommendation 2}

Examine the potential for an intensive and comprehensive Summer Bridge program to help student-athletes - especially those who are academically fragilesuccessfully transition into the academic and social rigors of life on a college campus.

Our analysis indicates that first-semester performance is the most critical predictor of long-term academic success for student-athletes. Similar results have been discovered in studies conducted by General College where first-semester GPA was found to be the only variable that strongly correlated with academic performance. In addition, anecdotal evidence gleaned from conversations with student-athletes indicates that the increase in workload and intensity from high school to college is vastly underestimated as a barrier to success.

Beyond anecdotal evidence, we examined the literature on the efficacy of summer bridge programs in general, and as related to student-athletes in particular. We discovered that for at least two decades, research has described the outcomes of various summer bridge programs for students who are believed to benefit from additional support as they transition into college life. Many of these programs have been aimed at students of color. For example, the University of Minnesota, Morris, Gateway Program is a 4-week summer initiative for African American and American Indian students. The students who participated in this program graduated at the same rate as White students (Risku, 2002). In addition, Zhang and RiCharde (1999) found that participants in a summer program earned higher first-year GPAs and were more likely to return to school compared with a similar group of nonparticipants. In reviewing the outcomes of UC Berkeley's affirmative action program, Carroll, Tyson, and Lumas (2000) suggest that participation 
in the summer bridge program was an important contributor to student success. Despite the general consensus that bridge programs are effective, caution should be used when interpreting results evaluating their impact because participants often continue to receive support services beyond summer programs, which might also contribute to academic success.

Athletes have been included in summer bridge programs when their characteristics match those of other students receiving support. Scholars such as Carodine, Almond, and Gratto (2001), recommend that athletes participate in orientation programs with other students to reduce their isolation and reinforce their identities as students. In a recent study, Hollis (2001-2002) queried 91 heads of athlete academic support departments at Division I institutions. She examined specific types of services and staff in the unit and the amount of space, budget, and administrative support for the unit. These variables were then used to predict graduation rates for student-athletes. Having a summer bridge program for new students was associated with higher graduation rates, suggesting that this approach can be considered "best practice."

Based upon these and other findings, we believe that summer bridge programs must be thoroughly examined as a way to help at-risk student-athletes in particular as they transition into the University community. Academically fragile students are often "at risk" not because they lack the cognitive ability necessary to complete a degree, but because they are under-prepared, lack verbal and quantitative skills, and lack the social and cultural experiences needed to succeed within the higher education community. Frequently, at-risk student-athletes have incurred a study deficit over their high school years, one that prevents them from hitting the ground running. A summer bridge program could help "jump start” their academic careers. In addition, a summer bridge program could be the initial phase of a broader tracking system for first-year students who are considered at risk. Such a tracking system should include a means by which advisors and tutors get more timely feedback on in-class performance, and should focus on freshman-level courses with a particular emphasis on math and science courses, writing, and other classes considered "gateway courses."

While there are only limited data demonstrating the effectiveness of summer bridge programs, we found that a number of Division I schools-we looked at the University of Iowa and the University of Washington in particular-have such programs for at-risk freshman, both student-athletes and non student-athletes alike. However, we also found that one reason there are so little actual data-not to mention research studies - related to these types of programs for student-athletes is that the NCAA only began allowing such initiatives in 2001 and confined these practices to men's and women's basketball; summer bridge programs were extended to all sports beginning in the summer of 2005.

At the $\mathrm{U}$ of $\mathrm{M}$, we have some data suggesting that simply bringing entering at-risk student-athletes to campus the summer before their freshman year does not automatically help their long-term academic success. This appears to be the result of the limited number of appropriate summer courses currently available, the time commitments these students give to athletics, and the lack of a formal program. In sum, we urge the University to make sure that any summer bridge initiative that is undertaken involves a serious, comprehensive, and systems-wide approach. Done correctly, such an initiative could become the first step in creating, 
implementing, and monitoring early intervention and individualized programs for those student-athletes most at risk. Exposure to a comprehensive summer bridge program may also enhance and integrate the academic expectations and motivations of student-athletes and foster a commitment to accountability in specific, measurable terms.

The data provided below come from the University's recent efforts to offer some kind of transition initiative for student-athletes the summer before they enter the U. Note that these efforts do not involve any formal, systematic program. Nevertheless, we gathered relevant data to see what trends, if any, were developing as a way to lay the foundation for future summer bridge programs.

- Student-athletes were enrolled in an "informal" summer program beginning in 2001 through summer, 2006

- A total of 44 student-athletes enrolled, and of this total, $26(61 \%)$ were at risk

- The majority of student athletes came from men's and women's basketball and football

- Pathways of entrance clustered in the following colleges: CEHD 35\% $(n=15)$; CLA 30\% $(n=13)$; GC 19\% $(n=8)$; CCE 14\% $(n=6)$; CHE $2 \%(n=1)$

- Number of credits attempted across all summers ranged from 2 to 10, with an average of 6.3 credits attempted

- Number of credits earned across all summers ranged from 2 to 10, with an average of 5.7 credits earned

- GPAs across all summers ranged from 1.44 to 4.0 with an average of 2.84

- First-semester GPAs across all summers ranged from 0.97 to 3.5 with an average of 2.52

\section{Recommendation 3}

Increase access to academic programs relevant to student-athletes as a way to increase their interest and motivation, leading to better academic outcomes.

We support the notion that once student-athletes are admitted, the University has an obligation to provide academic majors and programs in which they have an interest. Research has shown that the general institutional culture and conditions that influence the overall graduation rate at any academic institution account for $80 \%$ of the graduation rate of its athletes. A key component of "culture and conditions" is making available those areas of study that will significantly increase a student's desire to learn. In short, student-athletes are more likely to succeed if they are engaged in academic fields of study they find interesting and motivating and if they see a relevant link to their future careers.

Many of our ideas on "relevance" stem not only from anecdotal evidence provided by members of the task force who have "expert knowledge" as academic advisors or athletic administrators, but also from individual transcript analyses, especially of those student-athletes who were predicted not to succeed but did so. Transcript analysis revealed that overachieving student-athletes generally clustered into six academic majors: 
- Inter-College Program

- Business and Marketing Education

- Kinesiology

- Sport Studies

- Family Social Studies

- Communication Studies

A common thread throughout these majors is that they allow a student-athlete to integrate his or her experience and interest in the world of sports with their academic areas of interest. In addition, these majors have accessible GPA requirements - an overall GPA of 2.0 to both enter and graduate - and are often more flexible in terms of other entrance requirements and class schedules.

One major barrier to success for underperforming students has to do with the point made above regarding GPA requirements. Conversations with McNamara advising staff indicate that many student-athletes, particularly those at risk, want to major in academic areas such as Sport Management/Studies. Because acceptance into some relevant majors require GPAs higher than 2.0, many student-athletes go into Business Marketing Education (BME) in CEHD or Communication Studies (CS) in CLA. They choose these majors, in part, because they are interested in business (BME) or mass communication (CS), but what they are primarily interested in is the business of sport (e.g., sport marketing and promotion) or communicating about sport (e.g., sports journalism). We therefore urge Central Administration-after appropriate consultation with relevant Deans, Department Chairs, and faculty - to expand access to traditional majors and to explore the development of intra- and inter-college majors/emphasis areas that would significantly increase student-athletes' motivation to succeed academically. For example, related to this latter point, a student-athlete might combine a major in BME (Department of Work and Human Resource Education) with an emphasis area in Sport Studies (School of Kinesiology). Such an approach is consistent with one of the major goals of Strategic Positioning-interdisciplinary, collaborative initiatives.

\section{Recommendation 4}

Intensify efforts to track, engage, and provide opportunities to former studentathletes who have left the $U$ without graduating but who have accumulated enough credit hours so that graduation is well within reach.

During the course of our investigation we learned about a group of studentathletes who achieved academic success but remain largely invisible throughout mainstream media and in our public consciousness. We speak of student-athletes who left the University without graduating, only to return (in some cases, after many years) and earn their undergraduate degrees. This is something that both the student-athletes themselves and the University can take great pride in. We urge Central Administration to build on efforts already in place to significantly increase the graduation rates of these student-athletes because, in spite of recent successes (key findings for those who have returned and obtained their degrees are provided on page 119), much work remains. 
From 1999 through summer, 2006, approximately 27\% (385/1450) of all student-athletes enrolled at the U of M left without obtaining their degrees. Some of these individuals went into professional sports or transferred to other institutions. We focused our efforts on those student-athletes who had accumulated enough credit hours to have the possibility of graduation within reach. "Enough credit hours" was defined as 100+ academic credit hours; 48 former student-athletes fit that criterion. For the sake of brevity and clarity, we refer below to student-athletes who left the U without obtaining their degrees but accumulated a significant number of credit hours as "leavers" (key findings for student-athletes in this category are provided on page 120).

Currently, the University makes use of the Student-Athlete Opportunity Fund to encourage and assist former student-athletes to return to the $U$ and obtain their degrees. This fund was established by the NCAA to provide direct financial benefits to student-athletes and their families. Funds are distributed by individual conferences with the intent of providing maximum flexibility in their use. The Opportunity Fund can be used to assist student-athletes in meeting financial needs that arise in conjunction with participation in intercollegiate athletics or enrollment in an academic curriculum. Examples where funds have been dispersed include degree completion programs and financial support for summer school programs.

At the University of Minnesota, the Student-Athlete Opportunity Fund has been a cornerstone of the Gopher Graduation Initiative overseen by key personnel in the Athletic Department. Key goals of this initiative include:

Being proactive in tracking and updating relevant information related to leavers. This goal will be more easily achieved with the implementation of Recommendation 1;

Identifying those individuals — teachers, coaches, staff, community memberswho have established close relationships with a leaver and empowering them to encourage leavers to return to the $\mathrm{U}$; and

Working with coaches, staff, alumni groups, and the NCAA (e.g., use of their annual graduation reports) to identify and target leavers who dropped out of the U before the advent of PeopleSoft in 1999.

We applaud the efforts and early successes of the Gopher Graduation Initiative, but feel this important project would be strengthened if Central Administration, in consultation with the Athletic Department, appoints an individual whose primary responsibility would be to expand and oversee this and other efforts aimed at improving the graduate rates of former student-athletes. This individual's responsibilities would include, but not be limited to:

Creating a pool of mentors to help negotiate the process of readmission;

Providing and coordinating appropriate levels of assistance related to academic support and advising;

Identifying barriers to reentry, as well as support mechanisms that will ensure academic success; 
Conducting interviews with student-athletes who dropped out but subsequently returned to the $\mathrm{U}$ and graduated; and

Developing one-on-one peer relationships between academically successful student-athletes and leavers.

Regarding the suggestion related to conducting interviews, information gleaned from these encounters can help to develop and implement specific pathways and strategies for getting other student-athletes to return and graduate.

Regarding the suggestion to develop one-on-one peer relationships, a review of research conducted by Pascarella and Terenzini (2005) suggests that peers can have important effects on students' academic experience. Watt and Moore (2001) found that although many athletes spend a great deal of time with other athletes, their strong identification with an athletic peer group can be beneficial, including an increase in tolerance, respect for differences, and support for the problems they share such as balancing schedules.

We believe that with key leadership and appropriate levels of assistance, an initiative created specifically for these particular student-athletes can become a model for all students who face academic challenges at the University.

\section{Key Findings Related to Student-Athletes Who Returned to the $\mathrm{U}$ of $\mathrm{M}$ and Graduated}

Though the information provided below is incomplete because of some missing data, we have highlighted key trends related to those student-athletes who returned and earned their degrees.

- A total of 24 student-athletes have returned and graduated over the last 3 years-75\% male; $25 \%$ female

- For male athletes, 50\% were in football or basketball, with hockey, wrestling, and track \& field represented; for female athletes, $33 \%$ were in basketball with soccer, swimming, hockey, and track \& field represented

- One student-athlete dropped out in 1983; others did so as recently as 2005. The average duration between drop out and return was 3 years- 2 months, with a range of 9 months to 21 years- 6 months

- The range of time it took from "return to graduate" was 4 months to 2 years- 9 months, with an average of 1 year- 8 months

- Colleges from which student-athletes graduated: CLA (33\%); CCE (25\%); CEHD (25\%); IT (8\%); and CFANS (4\%)

- Majors earned: ICP (25\%); Kinesiology/Sport Studies (21\%); Mechanical/ Electrical Engineering (8\%); History, American Studies, Child Psychology, Psychology, Communications Studies, Philosophy, and Natural Resources $(<1 \%)$

- Overall GPAs ranged from 2.08 to 3.83 with an average GPA of 2.54 


\section{Key Findings Related to Student-Athletes Who Left the $U$ of $M$ and Have Not Returned to Graduate}

The information below highlights trends related to "leavers"- -student-athletes who left the $\mathrm{U}$ without graduating, did not transfer from the $\mathrm{U}$ of $\mathrm{M}$ to another school, and accumulated at least 100 credit hours.

- A total of 48 student-athletes fall into this category-75\% male; $25 \%$ female

- For male athletes, 36\% participated in football, $17 \%$ in hockey, $11 \%$ in basketball and swimming, with baseball, golf, gymnastics, and track \& field represented

- For female athletes, 58\% participated in soccer and rowing, with softball, swimming, tennis, and track \& field represented

- Overall, $46 \%$ of "leavers" were at-risk student-athletes, $56 \%$ of whom were male, $17 \%$ of whom were female

- $60 \%$ of "leavers" entered through GC, followed by $27 \%$ through CLA; $6 \%$ through CEHD; $4 \%$ through IT; <1\% through CFANS

- $38 \%$ of "leavers" were last enrolled in CEHD, followed by $31 \%$ in CLA; $19 \%$ in CCE; and $<1 \%$ in IT, GC, CHE, and CALA

- $69 \%$ of "leavers" were White, followed by $25 \%$ who were African American; less than $1 \%$ of "leavers" were Hispanic and international student-athletes

- Total number of credit hours earned by "leavers" ranged from 100 to 149, with the average number of total credit hours equaling 121.81

- Cumulative GPAs of "leavers" ranged from 1.49 to 3.54, with the average cumulative GPA equaling 2.53

We should emphasize that "leavers" represented only $5.7 \%$ of all studentathletes who enrolled at the $\mathrm{U}$ of $\mathrm{M}$ between 1999 and 2006. Interestingly, when compared with undergraduate non student-athletes, the percentage of "leavers" is even higher-7.1\%. Why might this be the case? Closer examination of the data suggests this is because of the larger percentage of transfer students in the overall student body. That is, when one breaks down the percentage of "leavers" between incoming freshman and transfer students, for freshman, 5.3\% of student-athletes are "leavers" compared with $4.8 \%$ of non student-athletes; for transfers, $11.3 \%$ of student-athletes are "leavers" compared with $12.0 \%$ of non student-athletes. However, only about $6.4 \%$ of student-athletes are transfer students compared with $32 \%$ of the student body overall. This finding suggests that students transferring into the $\mathrm{U}$ of $\mathrm{M}$ are at a significantly greater risk of leaving without graduating regardless of whether they are student-athletes or not.

\section{Recommendation 5}

Strengthen current efforts to more fully integrate intercollegiate athletics with the broader University community by eliminating unnecessary barriers and creating structures and opportunities that promote a culture of integration. 
Recent efforts to integrate the culture of intercollegiate athletics with the University community at large are consistent with the Regents' policy, as well as the policies of faculty governance. For example, one of the guiding principles of the Regents Policy on Intercollegiate Athletics is that, "the University shall promote a culture that integrates Intercollegiate Athletics into the campus mainstream." Explicit acknowledgment of the desire to more fully integrate athletics is also reflected in the policies of the Advisory Committee on Athletics (ACA), a committee that provides oversight and consultation between faculty and the Department of Athletics:

[The ACA] strongly supports the integration of athletic administrators and coaches into the University governance structure. . . Efforts also must be made to insure that student-athletes are treated as integral members of the University community, eligible to participate in all its activities and to take full advantage of the opportunities and services that the University can provide to facilitate their development and graduation. (Advisory Committee on Athletics, 2003)

The ACA provides many examples of positive and appropriate interactions between faculty and coaches designed to more fully integrate athletics. Some examples include:

- Encouraging coaches and other staff in the Athletics Department to apply for membership on University-wide committees;

- Inviting coaches to departmental or collegiate sponsored forums or meetings where issues that are relevant to student-athletes are discussed;

- Providing opportunities for recruits to meet with faculty from colleges/departments where student-athletes hope to enroll;

- Broadening the Guest Coach program; and

- Encouraging student-athletes to invite faculty members to the annual studentathlete Scholars Banquet.

Because of the many academic scandals that have occurred in Division I college sports, "firewalls" have often (and appropriately) been erected between the academic side of the institution and athletic departments. The University of Minnesota is no exception. Though we recognize and support the need for strong oversight, it is also important to recognize that positive and significant interactions between coaches and faculty can (and should) exist. Indeed, such interactions can be critical to more completely integrating athletics into the University community as a whole.

Within the last few years there have been renewed efforts by the ACA and other units across the University to sponsor events that will foster interactions between academics and athletics. Preliminary results from these efforts suggest that people in athletics are eager to increase their involvement with the University community. These efforts help ensure that the discussions and ideas generated by the task force are continued, and that there is faculty "follow up" on all of our recommendations.

To maximize the efforts initiated by the ACA and faculty governance committees, we suggest that Central Administration in general, and the Office of the Provost in particular, take a proactive approach to encourage cooperation among 
faculty, coaches and academic and athletic staff. We believe that ongoing grassroots efforts by the faculty to foster such interaction will be substantially enhanced if faculty and athletic personnel see direct involvement at the highest levels of the University. Such involvement could include:

- Creating opportunities for academic and athletic personnel to discuss matters of mutual interest such as student-athlete graduation rates;

- Inviting coaches and athletic administrators to participate in events (e.g., orientation week) where new faculty and staff learn about the entire University community. It is vital to establish the culture of the $U$ as soon as new people arrive on campus; and

- Actively publicizing and promoting the many academic accomplishments of our student-athletes such as profiling student-athletes who make the Dean's list, graduate with honors, or receive all Big 10 academic honors.

\section{Implementations of Recommendations: 1-Year Update}

In January 2007, Professors Kane and Leo (Task Force cochairs) submitted the final report to President Bruininks and Provost Sullivan. The President and Provost thanked the Task Force members for their work, accepted all five recommendations, and made a commitment to ensuring that the recommendations would be implemented in a timely fashion. Toward that end, Provost Sullivan convened five separate committees, or implementation teams (one per recommendation), to determine how best to implement each of the recommendations. It should be emphasized that the level of commitment from Central Administration toward making these recommendations become a reality is reflected in those appointed as chairs of the respective committees_-Vice Provosts, Deans, and Department Chairs.

\section{Recommendation 1: Formalize, Standardize, and Streamline Data Collection by Creating a Centralized Database}

The implementation team recommended creating a data collection analyst position to "formalize, standardize, and streamline data collection of student-athletes' academic performance." Funding for the position would be split between Central Administration and the Department of Athletics. The Senior Vice Provost for Academic Affairs requested funding — as part of the FY 2009 Undergraduate Education Budget submission - to support half of a position for the individual who will oversee this initiative. A position description has been created; the new hire will report to the Director of the McNamara Student Advising Center for student-athletes. The University plans to fill the position in the Fall of 2008.

\section{Recommendation 2: Develop an Intensive and Comprehensive Summer Bridge Program}

"Bridge to Academic Excellence" is an innovative (and new) transitional program designed to prepare recent high-school graduates for the academic rigors of the 
University of Minnesota. Students have been selected to participate in the program because of their potential to achieve at the highest level. The Bridge to Academic Excellence program provides a rigorous and positive academic experience from which new college students can build a foundation for future college success. It also works to ensure that students gain the skills and support they need to reach their full academic potential. U of M faculty are the primary instructors while staff provide academic support, including advising, tutoring, and career planning.

Eighteen student-athletes began the inaugural program in summer 2007, 16 of whom successfully completed the program, which was instituted as part of the year-long Bridge to Academic Excellence program. Two student-athletes left the program for reasons unrelated to academics. All students enrolled for six academic credits (two courses) over the summer. The overall GPA (on a 4-point scale) for student-athletes was 2.94 and for non student-athletes $(n=66)$ it was 3.61.

\section{Recommendation 3: Increase Access to Academic Programs Relevant to Student-Athletes}

The implementation team's primary focus to date has been the identification of barriers to access for desired programs, as well as the creation of possible solutions to eliminate or mitigate the barriers. Academic and nonacademic barriers that student-athletes face were evaluated by program area and included the following factors: Access is limited to many of the desired academic programs (e.g., Sport Management) because they do not admit freshmen, emphasize GPA in admissions criteria, and require students to declare their major to be admitted to courses in the major. In addition, some of the relevant majors require a large number of credits, have a single annual admission period, and have smaller class sizes in many desired courses because of space limitations. Thus, the implementation team is considering the following recommendations:

- Consider freshman admission to the College of Education and Human Development and some specific majors, which would be supported by a general curricula that does not unduly inhibit students from transferring to another major or college;

- Increase the frequency of application and admission deadlines to at least two per year;

- Explore changes in admission criteria and processes to reduce unnecessary hurdles and expand the criteria beyond sole reliance on GPA;

- Adjust scheduling of course offerings to reduce bottlenecks and delays and provide flexibility in time of day where possible;

- Review the total number of major course credits required in identified CEHD and CLA majors and allow selected major courses to be open to all students so they can experience the field and possibly build it into their course of study;

- Evaluate the necessity of some existing required sequencing of courses within programs to provide greater flexibility to students;

- Examine the creation of minors in specified programs to allow greater flexibility and meet student needs/interests (such as in Sport Management and Business and Marketing Education with a sports emphasis); 
- In CEHD, consider creation of an "intra-college degree" in which the student, with an advisor, designs a degree program from a variety of CEHD "neighborhoods"; and

- Collect and review best practice models of existing "intra-college degrees" at other universities.

\section{Recommendation 4: Intensify Efforts to Track, Engage, and Provide Opportunities to Former Student-Athletes Who Left the $U$ Of M Without Graduating}

In 2007-2008, the implementation team began a new initiative: the Gopher Graduation Program, which identifies former student-athletes and proactively makes contact with them and encourages their return to complete the necessary coursework to obtain their degrees. The Gopher Graduation Program includes a review board that is responsible for oversight and for allocating resources where appropriate. Reviewboard members come from relevant athletic and academic units across the campus to maximize collaboration and provide appropriate and timely academic counseling and support as ways to foster the ultimate goal of having former student-athletes receive their degree. The program also identifies the best $\mathrm{U}$ of $\mathrm{M}$ point of contact (e.g., coach, MAC counselor, former professor) to establish a connection with a former student-athlete as a way to encourage his/her return.

Finally, the Department of Athletics has committed monies from its annual scholarship budget (where allowed under NCAA rules) and the Student-Athlete Opportunity Fund to pay for tuition for returning student-athletes. Applications are reviewed on a case-by-case basis by the review board and funds are approved where appropriate. The goal is to provide financial assistance to students that need it to complete their degrees. The $\mathrm{U}$ of $\mathrm{M}$ also relies on the NCAA's degreecompletion program, which offers financial assistance to applicants selected for the program; this NCAA process is provided to former student-athletes as an alternate opportunity for aid.

\section{Recommendation 5: Strengthen Current Efforts to Integrate Intercollegiate Athletics With the Broader $\mathrm{U}$ of M Community}

The implementation team, along with the ACA, developed a plan that would promote opportunities to foster positive interactions between academics and athletics. These opportunities include:

- Faculty/Coach lunch program at which topics of mutual concern are discussed;

- Designated faculty and staff appreciation days, which afford members of the University community the opportunity to purchase tickets at a discounted price before some of the athletic events. Information about the events is sent to all faculty and staff via e-mail from the chairs of the ACA and the ACA Subcommittee on Campus/Community Building;

- Meetings with coaches regarding efforts to promote faculty/staff appreciation days; 
- Complimentary tickets to a home football game for new faculty plus an "honorary coach program";

- Human interest stories featuring coaches in University publications; and

- Identifying academic units to "showcase" at athletic events.

The implementation team also put forth the following list of activities and interactions to more fully integrate faculty, staff, administrators, and coaches:

- Work with the Provost's Office to include the participation of coaches and athletics administrators in the new faculty orientation and with the Office of Human Resources for new staff orientations;

- Create a campus marketing strategy and ticket-pricing plan that facilitates and encourages faculty attendance and involvement in athletics programs and events;

- Enhance communication and exchange with the Student Athlete Advisory Committee (SAAC) regarding student perspectives on intercollegiate athletics;

- Encourage coaches and other P\&A staff in the Athletics Department who meet the eligibility criteria to apply for positions on University-wide committees;

- Encourage departments to invite coaches to departmental- or collegiate-level sponsored forums or meetings when issues relevant to student-athletes are discussed;

- Provide opportunities for student athletes and recruits to meet with faculty from various colleges and departments;

- Create a program allowing student-athletes to invite faculty members to annual events;

- Profile faculty in Intercollegiate Athletics media venues and events or create a "column" in the athletics department newsletter; and

- Encourage members of the ACA to attend athletics events and create a policy/ practice that makes it easier for them to do so.

\section{Conclusions and Recommendations for Future Success}

Intercollegiate athletics can play a critical role in the University's efforts to become one of the top three public research universities in the world. The Board of Regents explicitly acknowledges the various and important ways that college sports connect the $\mathrm{U}$ to broad and deep constituencies:

Intercollegiate athletics fosters positive identification and goodwill for the state and its University among graduates, citizens of the state, and individuals across the country. This good will, public support, and identification help the University serve its varied missions in all its activities. (University of Minnesota Board of Regents, 1986)

The Athletic Department also recognizes its importance-and obligation-in advancing the success and impact of the University. A key component of the 
Department's mission is to serve as a "window to the U." This window should reveal not only the athletic successes of our student-athletes but their academic accomplishments as well. A strong and overt commitment to the academic performance of student-athletes underscores the University's overall commitment to undergraduate education and building a talented, promising, and highly qualified student body from diverse backgrounds.

We believe the University is well positioned to implement our recommendations immediately. As mentioned in the introduction, the President and Provost have placed the academic success of our students at the center of Strategic Positioning. As part of this effort, the Provost recently announced a number of academic initiatives that will enhance ongoing efforts to improve student experiences and outcomes, including overall graduation rates. Such efforts are already showing signs of progress as reflected in Figure 5.

As this figure indicates, the 4-year undergraduate graduation rate for non student-athletes is higher than for student-athletes, though their 5-year graduation rates are nearly identical. At 6 years, the comparative trend is reversed. Beyond these particular trends, longitudinal data on graduation rates from the freshman classes of 1999-2002 show that the 4-year graduation rate for both student-athletes and non student-athletes has been increasing, whereas the 5-year and higher rates remain relatively flat. Specifically, the 4-year rate for these three student-athlete cohorts increased from $21.4 \%$ to $32.5 \%$ to $37 \%$, respectively, while the 5-year rate went from $64.2 \%$ to $63.2 \%$ to $58.2 \%$. For non student-athletes the 4-year rate increased from $32.4 \%$ to $37 \%$ to $41.2 \%$, while the 5 -year rate has gone from $56 \%$ to $60.8 \%$ to $58.1 \%$.

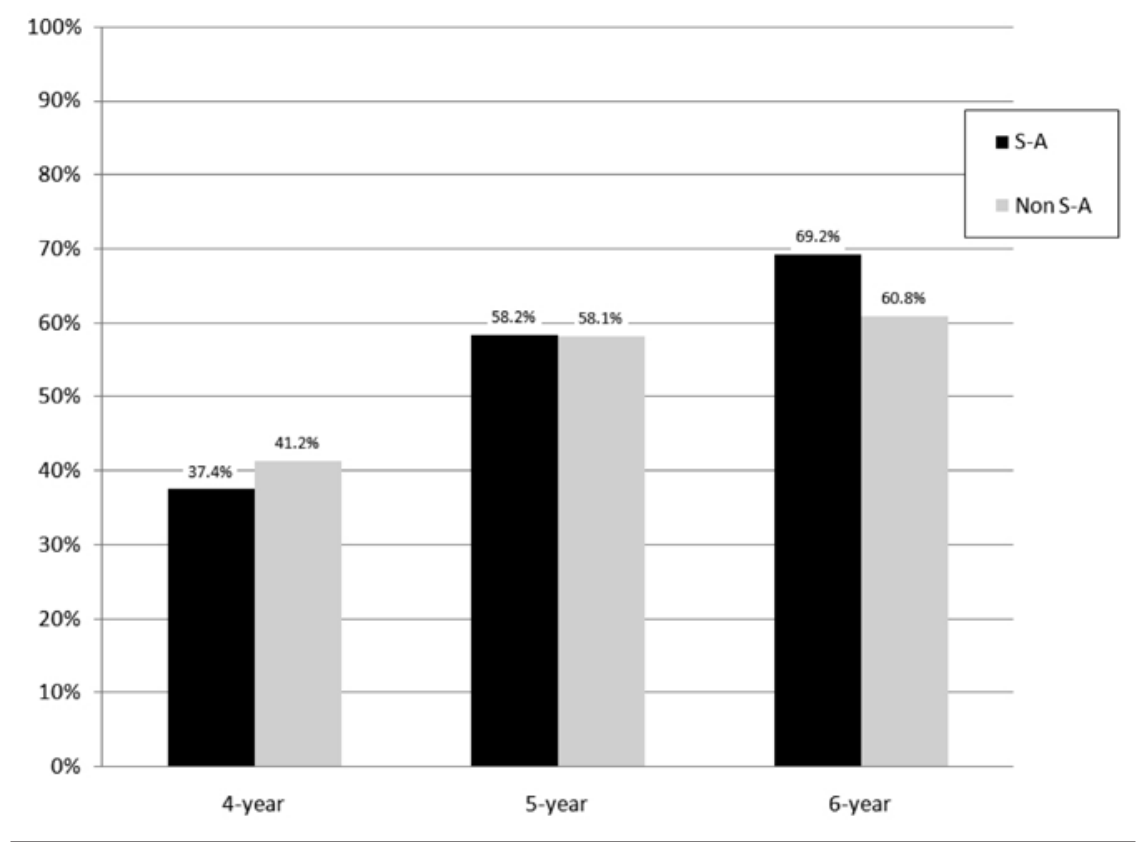

Figure 5 - Comparative data for graduation rates for student-athletes vs. non studentathletes. 
Interestingly, for non student-athletes, there was little difference between the 5- $(58.1 \%)$ and 6-year $(60.8 \%)$ graduation rates. In sharp contrast was the trend for student-athletes in that the additional year was important: For 2006, the 5-year graduation rate was $58.2 \%$ while the 6-year rate was $69.2 \%$.

When referring to Strategic Positioning, the President and Provost often remind us that the status quo is unacceptable and that "to stay the same is to fall behind." Improving graduation rates for all students is an essential benchmark of this historic initiative. Targeting the academic performance of student-athletes is one important way for the University to achieve this important and worthy goal.

In conclusion, the changes our Task Force recommended-from upgrades in the infrastructure of data collection and analysis to critical investments in such ongoing efforts as the Gopher Graduation Initiative-are all focused on improving student-athletes' academic experiences and outcomes, including, most importantly, obtaining their college degrees. Successful implementation of our five recommendations will help ensure that the "view through the window" illuminates both the athletic and academic achievements of our student-athletes, as well as the efforts of our dedicated faculty, staff, and coaches in nurturing those achievements.

\section{Special Acknowledgments}

Tracy L. Fischer, Athletic Eligibility Coordinator, Office of the Registrar; Ronald L. Huesman, Assistant Department Director, Office of Institutional Research; John P. Kellogg, Assistant Director University-Wide, Office of Institutional Research; Nicole LaVoi, Associate Director, Tucker Center for Research on Girls \& Women in Sport; Jonathan Sweet, Program Associate, School of Kinesiology.

\section{References}

Advisory Committee on Athletics. (2003, October). ACA policy on integrating athletics \& academics. Minneapolis, MN: University of Minnesota.

Benford, R.D. (2007). The college sports reform movement: Reframing the "edutainment" industry. The Sociological Quarterly, 48, 1-28.

Box-Steffensmeier, J.M., \& Jones, B.S. (1994). Event history modeling: A guide for social scientists. Cambridge: Cambridge University Press.

Carodine, K., Almond, K.F., \& Gratto, K.K. (2001). College student athlete success both in and out of the classroom. New Directions for Student Services, 2001(93), 19-33.

Carroll, G., Tyson, K., \& Lumas, B. (2000). Those who got in the door: The University of California-Berkeley's affirmative action success story. The Journal of Negro Education, 69, 128-144.

Hollis, L.P. (2001-2002). Service ace? Which academic services and resources truly benefit student athletes? Journal of College Student Retention, 3(3), 265-284.

Hosick, M.B. (2007). Three-year APR data show teams on incline. National Collegiate Athletic Association News, 44(10), 11.

Institute of Diversity and Ethics in Sport. (2006). New study reveals marked improvements for the graduation rates for African-American student-athletes. Retrieved November 28, 2007, from http://www.bus.ucf.edu/sport/public/downloads/NSAD_2006_Study_ Grad_Rate_Improvements.pdf

Institute of Diversity and Ethics in Sport. (2007a). Keeping score when it counts: Graduation rates for 2007 NCAA Men's Division I Basketball tournament teams. Retrieved October 31, 2007, from http://www.bus.ucf.edu/sport/public/downloads/2007_Womens_Basketball_Tournament.pdf 
Institute of Diversity and Ethics in Sport. (2007b). Keeping score when it counts: Graduation rates for 2007 NCAA Women's Division I Basketball tournament teams. Retrieved October 31, 2007, from http://www.bus.ucf.edu/sport/public/downloads/2007_Mens_ Basketball_Tournament.pdf

Matheson, V.A. (2007). Research note: Athletic graduation rates and Simpson's paradox. Economics of Education Review, 26, 516-520.

Melendez, M.C. (2007). The influence of athletic participation on the college adjustment on freshman and sophomore student athletes. College Student Retention, 8(1), 39-55.

National Collegiate Athletic Association. (2007a). Defining academic success. Retrieved November 18, 2007, from http://www2.ncaa.org/portal/academics_and_athletes/education_and_research/academic_reform/defining_academic_reform.html

National Collegiate Athletic Association. (2007b). National and sport-group three-year APR averages. Retrieved October 31, 2007, from http://www2.ncaa.org/portal/ academics_and_athletes/education_and_research/academic_reform/apr/2005-06/ three_year_apr_averages.pdf

National Collegiate Athletic Association. (2007c). NCAA Division I graduation success rates. Retrieved October 31, 2007, from http://web1.ncaa.org/app_data/instAggr2007/1_0.pdf

National Collegiate Athletic Association. (2007d). Six-year trends in graduation success rate at NCAA Division I institutions. Retrieved October 31, 2007, from http://www2. ncaa.org/portal/academics_and_athletes/education_and_research/academic_reform/ gsr/gsrSixYearTrends.pdf

Pascarella, E.T., \& Terenzini, P.T. (2005). How college affects students: A third decade of research. San Francisco: Jossey-Bass.

Radcliffe, P.M., Huesman, R.L., \& Kellogg, J.P. (2007a, October). Identifying students at risk: Utilizing survival analysis to study student athlete attrition. Paper presented at the National Symposium on Student Retention. Albuquerque, NM.

Radcliffe, P.M., Huesman, R.L., \& Kellogg, J.P. (2007b, November). Modeling the incidence and timing of student attrition: A survival analysis approach to retention analysis. Paper presented at the Association of Institutional Research of the Upper Midwest, Bloomington, MN.

Rishe, P.J. (2003). A reexamination of how athletic success impacts graduation rates: Comparing student-athletes to all other undergraduates. American Journal of Economics and Sociology, 62, 407-427.

Risku, M. (2002). A bridge program for educationally disadvantaged Indian and African Americans. In: An imperfect world: Resonance from the nation's violence, 2002 Monograph Series. Houston, TX. Retrieved September 20, 2006, from ERIC database number ED4774 17.

Schmidt, P., \& Witte, A.D. (1988). Predicting recidivism using survival models. New York: Springer-Verlag.

Shulman, J.L., \& Bowen, W.G. (2001). The game of life. Princeton, NJ: Princeton University Press.

University of Minnesota Board of Regents. (1986, September 11-12). Minutes of the Board of Regents' meeting and regents' committee meetings, report of the staff and student affairs committee (p. 74). Retrieved October 15, 2006 from http://conservancy.umn. edu/bitstream/252/1/UNA19860911.pdf

Watt, S.K., \& Moore, J.L., III. (2001). Who are student athletes? New Directions for Student Services, 2001(93), 7-18.

Zhang, Z., \& RiCharde, R. S. (1999). Increasing retention and achievement: A summer transition program at work. Paper presented at the Annual Meeting of the Association for Institutional Research, Seattle, WA. Retrieved September 20, 2006, from ERIC database number ED43.5620. 


\section{Appendix A \\ Programs and Offices Represented by Committee Membership on the Task Force}

Mary Jo Kane, Cochair

Professor and Director, School of Kinesiology

Vice-chair, University Senate

Perry H. Leo, Cochair

Professor, Aerospace Engineering \& Mechanics

Chair, Faculty Athletic Oversight Committee on Intercollegiate Athletics (FAOCIA)

C. Josh Borowicz

Senior Academic Advisor

CCE/Student Services and Advising

Heidi Meyer

Assistant Director of Admissions

General Recruitment, Office of Admissions

Mark Nelson

Director, McNamara Academic Center

Linda J. Brady

Professor, Food Science and Nutrition

Faculty Representative, Intercollegiate Athletics

J. T. Bruett

Associate Director, Athletics Compliance Office

James J. Rowan

Assistant Director, Office of Admissions

L. Victor Collins

Director, Martin Luther King Program

Regina Sullivan

Associate Director, Intercollegiate Athletics

Lynn K. Holleran (Ex Officio)

Associate to the Vice President \& Chief of Staff

Office of the President

Patrick N. Troup

Director, Multicultural/Academic Affairs

Frank Kara

Director, Athletics Compliance Office

Cathrine A. Wambach

Associate Professor, Postsecondary Teaching and Learning

Leo E. Lewis

Associate Athletic Director

Intercollegiate Athletics 